\title{
Article
}

\section{The Belt and Road Initiative and the Common Heritage of Mankind: Some Preliminary Observations}

Zou, Keyuan and QIU, Wenxian

Available at http://clok.uclan.ac.uk/24063/

Zou, Keyuan ORCID: 0000-0002-2868-4948 and QIU, Wenxian (2018) The Belt and Road Initiative and the Common Heritage of Mankind: Some Preliminary Observations. Chinese Journal of International Law, 17 (3). pp. 749-756. ISSN $1540-1650$

It is advisable to refer to the publisher's version if you intend to cite from the work. http://dx.doi.org/10.1093/chinesejil/jmy021

For more information about UCLan's research in this area go to http://www.uclan.ac.uk/researchgroups/ and search for <name of research Group>.

For information about Research generally at UCLan please go to http://www.uclan.ac.uk/research/

All outputs in CLoK are protected by Intellectual Property Rights law, including Copyright law. Copyright, IPR and Moral Rights for the works on this site are retained by the individual authors and/or other copyright owners. Terms and conditions for use of this material are defined in the policies page.

\section{CLoK}

Central Lancashire online Knowledge www.clok.uclan.ac.uk

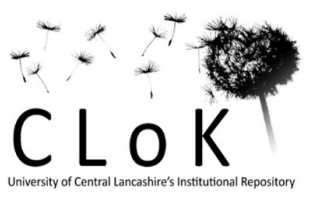




\title{
Editorial Comments
}

\section{The Belt and Road Initiative and the Common Heritage of Mankind: Some Preliminary Observations}

\author{
ZOU Keyuan* and QIU Wenxian**
}

\begin{abstract}
With the development of global science and technology, the international legal concept of "the common heritage of mankind" (CHM) encounters some dilemma in practice. This editorial comment attempts to discuss the ongoing developments of the $\mathrm{CHM}$ concept in the context of the Belt and Road Initiative (BRI) put forward by China, and then the interplay between the two concepts. It is argued that the inherent elements of the CHM concept, such as co-management, co-benefit, and co-participation, are well reflected in the BRI. Moreover, the BRI can also reinforce the dynamic extension of the CHM concept in the above three key elements. As a new international public good, the BRI is aimed at reasonable allocation and sharing of international resources following the CHM concept, and correspondingly this concept can strengthen the theoretical basis of the BRI facilitating its entry into the centre of the international stage.
\end{abstract}

\section{Introduction}

1. The concept of the common heritage of mankind (CHM) makes human common interest possible in international law. It has been said that the greatest contribution of the CHM is to consider all mankind as a

\footnotetext{
* Harris Professor of International Law, University of Central Lancashire, UK; Deputy Editor-in-Chief of this Journal.

** Assistant Professor at Guanghua Law School, Zhejiang University, China.
} 
whole, which could help us to explore a new type of international law. ${ }^{1}$ The 21st century, an era with a-high-speed development, makes the human living environment closer to the ecological bottom line and the common interests of mankind become a worldwide focus in dealing with many global problems. As K. Morrow states, "we have no choice but to promote sustainable management of natural resources and ecosystems in the face of many new and emerging challenges:". ${ }^{2}$ Therefore, the development of the CHM concept/principle should keep pace with the common interests of mankind in the framework of international law. Here, we try to focus on the interactive relations between the $\mathrm{CHM}$ principle and the Belt and the Road Initiative (BRI) initiated by Chinese President XI Jinping. Specifically, there are three questions to answer: firstlyFirstly, what kind of dilemma has the CHM principle met in its implementation due to scientific and technological developments? Secondly, in order to overcome the dilemma, what factors or variables should be considered in enhancing the effectiveness of the CHM principle? Finally, as a special carrier as well as an international public product, what can the BRI contribute to the development of the $\mathrm{CHM}$ principle?

\section{Emergence of the CHM as a legal concept}

2. There are three aspects in the CHM's emergence: (1) rapid progress of science and technology, rapid social productivity improvement and the scope expansion of human activities; (2)_rise of the new type of international economic relations and global interdependence; and (3) changed structure of the international community with a large number of independent nations after the Second World War.

3. The concept of CHM firstly appeared at the First UN Conference on the Law of the Sea, where Prince Wan Waithayakon of Thailand used the specific expression "common heritage" in his opening

1 GAOLanjun, Guojifa de JiazhiLun[Value of International Law] (2006), 122 (in Chinese).

2 Karen Morrow, Rio+20, the Green Economy and Re-orienting Sustainable Development, 14 Environment Law Review (2012), 279-297. 
remarks to ensure the preservation of marine resources as the heritage for the benefit of all. However, this concept did not attract much attention from the international community until 1967 when Arvid Pardo, the former Ambassador of the Maltese Mission to the UN, formally proposed the CHM at the 22nd UN General Assembly referring to the seabed and ocean floor beyond national jurisdiction. Since then, the CHM concept has been accepted by the majority of the United Nations members and was incorporated into international law, such as the UN Convention on the Law of the $\mathrm{Sea}_{2}$ as a legal principle. The common goals that the human society pursues and common interests of human beings are well reflected in this newly emerging legal concept. As Tanaka observes, the CHM concept focuses on "mankind" from a new perspective concerning the interests sharing-shared beyond the State-toState system. ${ }^{3}$ It connects interests between the various subjects, such as the countries, the collectives and the individuals. Moreover, it offers a legitimate method to use valuable resources belonging to all mankind. According to its literal meaning, the elements of $\mathrm{CHM}$ can be interpreted as follows: (1) the principle is applied in the international public domain and contributes to sustainable development of the human society; (2) the principle could refer to various heritages, not only tangible assets but also intangible property; and (3) due to scientific and technologic developments, the principle steps into more areas of human development, such as ecological concerns, international security and global trade.

\section{Dilemma in the implementation of the CHM concept}

4. As the CHM has been reflected in the-treaties and international documents, there are some dilemmas in its practice. For example, the Moon Agreement seems to incorporate the CHM and embody each element well, but the effect of the relevant provisions are qualified by others in the agreement; ${ }^{4}$ the Antarctic Treaty contains partial elements

Yoshifumi Tanaka, The International Law of the Sea (2nd edn. 2015), 19.

Bradley Larschan and Bonnie C. Brennan, The Common Heritage of Mankind Principle in International Law, 21 Columbia JTL (1983), 329. 
of the CHM, but the Treaty decision system is in the exclusive control of the consultative parties. With the development of science and technology, the types of exploitable resources become more diversified in the international seabed. Should the microorganisms around the seabed hydrothermal vents with high industrial value be a CHM? With respect to the-outer space, should geostationary orbits be defined as a $\mathrm{CHM}$ and its benefits be shared by humankind?

_ 5. The aforementioned dilemma comes from the different practices in diverse nations and regions. In order to break through the predicament, it is useful to borrow the theory developed by Oswald Spengler that different permutations and combinations of the carbon atoms can form different products-common graphite or valuable diamonds. ${ }^{5}$ Based on this theory, the development of the CHM can be examined in two dimensions - core elements and dynamic extension, of which the former keeps the main features constant while the latter is more flexible.

\section{IV.-A. Core elements of the CHM}

6. According to Black's Law Dictionary, the CHM is a part of the Earth and the universe. It belongs to the common benefits of all human beings and should be reasonably protected, regardless of geographical locations. ${ }^{6}$ As a brand-new legal concept, it is different from res nullius or res communis. The three keywords in the CHM are "mankind", "common" and "heritage": all human beings as a collective subject in international law. It not only includes the present generation, but also future generations; not only people from developed countries but also from the developing countries. Heritage is the legal object of the CHM. It is worth noting that the common heritage referring to the outer space, the international seabed area and the Antarctic is a tangible resource. However, the meaning of heritage does not exclude intangible properties, such as culture. The way to manage the property is co-

5 Oswald Sprengler, The Decline of the West: Form and Actuality (1926), Chapter 1, 3-36.

6 Bryan A. Garner (ed.), Black's Law Dictionary (9th edn, 2009), 313. 
management, which emphasizes that there is a single subject rather than res communis of all countries.

7. Therefore, inherent elements of the CHM include the following. First, co-ownership. Nobody can keep the property for itself. The CHM should serve all human beings equally. Second, co-management. That is, a specific international organization should be appointed as an executing agency to serve a new international economic order. And third, common participation, mutual benefit and joint protection. Thus, we should bear in mind the inherent elements when applying the CHM concept: its goal is for common benefits; its nature is to reshape the international order after the rise of developing countries; the unique path to achieve its goal is that human beings participate jointly with the corresponding establishment of the international management organization for co-management; moreover, the whole international community should develop, manage and protect the resources in a coordinated manner.

\section{IV.B. Dynamic extension of the CHM}

8. As a legal principle, the CHM concept has been applied in different fields. However, it is difficult to solve the existing contradictions well by only depending on the inherent connotations. The depth and extent of the CHM concept should be discussed based on the common interests of all human beings at root. The interaction between the stability of the inherent elements and the variability of the dynamic factors should be focused on. Besides maintaining the magnetic force of the inherent elements, the CHM principle should be more suitable for the rapid development of science and technology through the extensive interpretation in according accordance with the different situations, inter alia, the regions, the societies and the objectives. This extensive interpretation is in line with the modified form proposed by Noyes to some degree. ${ }^{7}$ __Both the bottom rules of inherent elements and the extensive interpretation of the modified elements will be influenced by

7 See John E. Noyes, The Common Heritage of Mankind: Past, Present, and Future, 40 Denver Journal of International Law and Policy (2012), 469. 
the common faith in international law. They should not only conform to the principles of legal interpretation as well as the certainty in law, ${ }^{8}$ but also be injected with fresh factors to adapt to the new practical situations. As a special carrier en-for changing the external structure of the CHM principle, the BRI not only enriches the principle's inherent connotation, but also provides an excellent path to re-structure the dynamic factors.

\section{The BRI as a special carrier of $\mathrm{CHM}$}

9. In 2013, President XI Jinping made a proposal to build the Silk Road Economic Belt and Maritime Silk Road of the 21st century. With China as a core nation, this proposal could radiate out to the east, the west and the south. The BRI extends across national boundariesfrom China to foreign countries and promotes greatly regional cooperation. It is the inevitable outcome in line with the internal need of for economic development in emerging countries and environmental requirements of external economic imbalance, and has been endorsed by many neighboring countries and regions. The BRI is not a closed system with the a definite boundary. Its spatial regions involved should depend on the will of each sovereign entity. It is actually an international cooperative platform with openness and inclusiveness.

\section{V.-A. The essence of the BRI}

10. From an international perspective, the BRI is a special international public good in the community of a shared future (CSF) for mankind. The concept of CSF means that we should take into_consideration the influence on other nations and promote the common development of all countries. There is only one Earth that human beings rely on_and the international community will eventually become the CSF as time passes by. Facing a multipolar world with economic globalization and cultural diversity, the only way to solve the common problems is to manage and

8 LIANG_Huixing, MinfaJieshi Xue[Civil Hermeneutics] (1995),_246 (in Chinese). 
control the outbreaks of various non-traditional security issues including, inter alia, population explosion, environmental pollution, and resources and/or food shortage.

- 11. From the CSF perspective, the BRI will deliver benefits to form global values, reach international consensus and obtain common development of all mankind through capital flow, trade, historical continuation, cultural promotion and exchange of ideas. There are four elements with respect to this public good. First, a new view of rights on interdependence, equality and mutual trust. It requires the establishment of international mechanisms to cope with any human crisis. Second, a new view of common interest under economic globalization. The various interests among States begin to blend with the rapid development of global transmission mechanisms, which made make every country become a part of the interest chain. Third, a new view of sustainable development. It can not only meet the need of the contemporary people but also protect the offspring. And fourth, a new view of global governance in the process of globalization. With the-behavioral subjects such as the governments, inter/non-governmental organizations, and multinational companies, global mechanisms with moral restraints are regarded as the paths to propel the international community to be more equitable, reasonable and responsible. Therefore, the BRI is an efficient carrier of global values. The CHM can reflect the legal attributes and spirit for this public product._Both the BRI and the CHM promote the CSF consciousness across the world.

\section{V.B. Interplay between the BRI and the CHM}

12. There are three aspects in which that the BRI can be considered as a carrier of the CHM. Firstly, the main purpose of the BRI is to promote economic development and human prosperity. There is no doubt that the ancient Silk Road is a product of ancient economic exchanges and it reflected the need of human societies with low productivity. The BRI has become an economic corridor with the largest span and global trade network. Its economic property is completely consistent with the original intention of the CHM of common sharing. The BRI can help Asia become an "economic power station", and also bring win-win benefits 
for the whole world. For example, the Asian Infrastructure Investment Bank now has 66 member States and has coordinated to allocate international funds since 2015. As an international cooperative organization, this Bank supports_infrastructure projects including ports and offers a platform of resource distribution and sharing along the Belt and the Road. It plays an important role in international cooperation.

13. Secondly, the BRI is a carrier with a cultural connotation as part of the cultural heritage including, inter alia, peace, friendship, exchange ${ }_{2}$ and prosperity. On the one hand, culture and economy have been inseparable since ancient times. In a sense, the history of the ancient Silk Road is exactly the history of transmission, collision, integration and innovation with respect to the world's cultures. The ancient Silk Road wasis a main artery connecting cultures all over the world at that time. For example, the culture of Fujian Province in China is a hybrid culture with native culture, the Central Plain culture and the oceanic culture. This kind of hybrid culture becomes more open, more compatible and more diversified. On the other hand, as a lookingforward element in the BRI, culture is actually an essential component with the subjective consciousness in the social construction. It is an integrated part forinto consciousness, materials, intelligence and emotions within the whole community. ${ }^{9}$ Although the influence of cultural diversity in the international community is little reflected in traditional international law, cultural management and intercultural interaction have been a main character in the contemporary international relations with the rapid development of global integration. The international community members should fully understand the cultural diversity and differences among different nations and regions around the world. Therefore, as a driving force to promote international integration, the diversity of cultures may cause a huge impact on the concepts of international law.

14. Finally, economic and cultural globalization drives different

9 Edwin Egede, The Common Heritage of Mankind and the Sub-Saharan African Native Land Tenure System: A_ "Clash of Cultures" in the Interpretation of Concepts in International Law, 58 Journal of African Law (2014), 3 . 
national laws to get closer. When the legal reform becomes an effective way to attract foreign investors, it seems significant for the developing countries to prevent themselves from falling into the traps of dependent development. ${ }^{10}$ Following the third Trade Revolution, the BRI aims to construct a new legal product with the Silk Road/Belt as the special carrier. Its establishment will not only benefit the solution to "Today's Problem" mixed by international political issues, international economic issues and international legal issues, but also help to realize "Tomorrow's Conception" of land and sea coordination for a new stage with respect to the-international legal construction and development.

15. In a word, the BRI is consistent with the inherent elements of the CHM concept, such as common possession, common management and common participation. On this global sharing platform, the CHM concept not only maintains its core standard of "common interests", but also meets the high demand of the society and plays a significant role in more fields, including economic development, cultural transmission and ecological protection.

\section{Conclusion}

16. As a practical art, law can never eliminate divergences, solve disputes and adapt to the rapid development of the society just through fixed rules. Driven by economic and cultural globalization, the interpretation of the CHM concept in a static manner cannot meet the diversified legal practice any more. It is imperative to establish the dynamic structure of the CHM for the demand of the global legal order's reconstruction in accordance with the existing international law and the bottom line of the CHM's inherent elements.

17. As a multi-dimensional dynamic cooperative concept, the BRI can find its roots in the CHM. This initiative aims at the allocation of international resources reasonably along the geographical line. In accordance with the principle of common possession, common

10 GONG_Pixiang, Quanqiuhuayu_Zhongguo_Fazhi_Xiandaihua_[Globalization and Modernization of the Chinese Legal System], 6_Faxue_Yanjiu [Studies in Law] (2000), 39-40 (in Chinese). 
management and common participation, this initiative aims to improve the existing international economic order and achieve the positive development of international cooperation. Therefore, the BRI not only completely conforms to the inherent elements of the CHM, but also delivers benefits to remold the dynamic structure of the latter, so as to provide a new platform for global resources sharing and common governance. It emphasizes the essence of the international order as it ought to be and makes the an effective combination between the intercultural nature of international relations and the connotation of the $\mathrm{CHM}$ concept. Correspondingly, the CHM concept can react on the construction process of the BRI and make the initiative become a new legal product which the international community can use to actively participate in the reconstruction of the global legal order for shared interests and also shared responsibilities. Therefore, the BRI is considered as a timely carrier to further apply the CHM concept in practice. It may take time to see the effects of the interaction between the CHM and the BRI as well as their complimentary development, but one thing is sure: the BRI helps us to open a new dimension to look into the CHM principle/concept. 